\title{
Variables Influencing Spectators’ Desire to Stay at A Professional Golf Tournament In Japan
}

\author{
Yasuhiro Watanabe \\ Hiroshima University of Economics \\ E-Mail: yasu-watanabe0110@hue.ac.jp \\ Koji Matsumoto \\ Hiroshima University of Economics \\ E-Mail: kj-matsu@hue.ac.jp \\ Haruo Nogawa \\ Juntendo University \\ E-Mail: nogawa@sakura.juntendo.ac.jp
}

\begin{abstract}
The main purpose of this study is to examine the variables influencing golf spectators' desire to stay at a professional golf tournament in Japan. The data used in this project were based on a questionnaire administered to 1023 spectators at two professional golf tour tournaments near Tokyo; 991 of these questionnaires were returned. The results indicated that the variables that most affected the golf spectators' desire to stay at the event site were affection for the player, fondness for the game, the course itself, and hospitality and service management. Overall, the event operation of the tournament appeared to have the strongest impact on the spectators' desire to stay at the event site.
\end{abstract}

Keywords: Desire to Stay, Golf Spectator, Professional Golf Tour Tournament

\section{INTRODUCTION}

Spectators who enjoy spending time at an event are assumed to be more likely to return to that or a similar event (Wakefield \& Blodgett, 1994; Wakefield \& Sloan, 1995; Wakefield \& Blodgett, 1996). Conversely, negative experiences are likely to 
reduce their desire to stay at the event, may cause them to leave early and to not to return. Event services such as trade fairs, motor shows, and sporting events, generally require customers to spend extended periods of time in the physical surroundings of the service provider (Wakefield \& Blodgett, 1996).

In all of these above cases, the perceived quality of the market demand (e.g., the game itself, the players' performance) and the servicescape (i.e., the physical environment) may play an important role in determining consumer satisfaction, which in turn, influences how long they stay at the event, how much money they will spend, whether they will return in the future, and whether they will re-patronize the event's organizer (Bitner, 1992; Wakefield \& Sloan, 1995; Zhang, Pease, Hui, \& Michaud, 1995; Zhang, Lam, \& Connaughton, 2003; Zhang, Lam, Connaughton, Bennett, \& Smith, 2005). Likewise, other aspects of an event, such as food, charity, staff, scoreboards, and access may partly determine whether sports spectators will stay for the entire event or lose interest and leave early. Unlike a comparable expenditure on most tangible products, attendance at a sporting event assumes an intention to remain at the service event for an extended period of time.

From the individual spectator's perspective, the economic impact of this decision transcends the mere purchase of a game ticket; it includes complementary expenditures inside (parking, food, drink, and souvenirs) and outside (meals, transportation, shopping, and perhaps lodging) the event. Thus, when spectators attend games, the environment (i.e., the event management, which provides core products and peripheral services) may play a significant role in determining how much they enjoy their experience. However, there is little research in which sport spectators are used as subjects to indicate what strategies should be adopted to attract spectators to an event and to remain there. Unlike baseball or soccer games, professional golf tour tournaments take up an entire day, so spectators can expect to be there for at least 4-6 hours.

The purpose of this study is to explore the influence that the market demand and physical environment at professional golf tour tournaments in Japan have on the spectators' desire to remain at these events.

\section{BACKGROUND}

\section{Definition of Spectators' Desire to Stay}

Bitner (1992) suggested that the spatial layout and signage of a venue, affect the behavior of customers and reported that the physical environment affects the demands and expenditures of customers. Wakefield and Baker (1998) defined "desire to stay" 
as an action in "the place", and they found that the physical environment of a shopping center has a relatively strong influence on the desire of shoppers to remain there.

Spectators typically spend two to four hours at a stadium, and their experience of service quality and the physical environment influences both their desire to stay and their future attendance (Wakefield et al., 1996). However, for researchers, there is still uncertainty as to what kinds of demands and environments influence the spectators' desire to stay at a sporting event. The number of studies devoted to spectators of golf, whose characteristics are unlike those of other spectator sports, is insufficient because a golf tournament by itself does not reveal the factors that influence the spectators' desire to stay.

Further, in past research, there has been no attention to what kind of influence the needs and wants of spectators have on their desire to stay. Although there have been a few studies on the physical environment of stadiums (Wakefield \& Sloan, 1995; Wakefield et al., 1996), they do not take into consideration the core product for spectators, which is to see the game or their favorite players. Therefore, when planning a sporting event, it is necessary to construct a "stay behavior model" that is attentive to the "spectators' desire to stay" in addition to what spectators need and want. It should be noted that, in this study, the "spectators' desire to stay" is defined as the desire of sports spectators to remain at an event site.

\section{Market Demand (Core Product) At Sports Events}

A variety of spectator characteristics have been identified by using sports consumer motive scales (e.g., Milne \& McDonald, 1999; Trail \& James, 2001; Funk, Mahony, Nakazawa, \& Hirakawa, 2001). Although these studies have elucidated the reasons that bring spectators to sports events, they cannot provide an understanding of spectator behavior after the spectator has actually arrived. Spectators' motives determine their behavior, but spectator motive scales cannot evaluate what spectators actually do once they are at the event. To compensate for this deficiency, some researchers have measured spectators' market demands instead of examining spectators' motives.

Market demand has been defined as spectator expectations of the important attributes of a core product (Braunstein, Zhang, Trail \& Gibson, 2005; Zhang et al., 1995, 2003). In addition, market demand is influenced by a cluster of 'pull factors' that the event can offer (Braunstein et al., 2005). Pull factors are tangible marketing variables that are directly related to the core products or peripheral services of a sports event (Zhang et al., 2003). According to Braunstein et al. (2005) and Mullin, Hardy, 
and Sutton (2007), the core product consists of the items that influence the characteristics of the event, for example, the quality of the game or the presence of a star player. The quality of core products and related services plays an important role in maintaining and increasing spectator attendance.

Prior studies of sports spectators have examined the effect of the attention paid to an individual player on sports spectators (e.g., Funk et al., 2001; Mahony \& Moorman, 2000; Zhang et al., 1995, Zhang, Pease, Smith, Lee, Lam, \& Jambor, 1997). Zhang et al. $(1995,1997)$ reported that the charm of the game (e.g., the player) influences the spectators at an event. Mahony and Moorman (2000) reported that attachment to players can be strong enough to influence spectator behavior. Funk et al's (2001) Sport Interest Inventory (SII) includes the factor "interest in player", and used it to clarify sports consumption behavior. These studies suggest that players affect the attendance of spectators.

Hansen and Gauthier conducted major studies of golf spectators at professional tournaments $(1993,1994)$. They identified the following core products in a professional golf tour tournament: "watching close to the players," "watching silently during play," "walking the course with the players", and "the scenery of the course". Hansen and Gauthier $(1993,1994)$ reported that tourney products include "seeing the game close to the players," "spectators oneself like golf," and "learning the skills of the players". In addition, Hansen and Gauthier $(1993,1994)$ stated that golf spectators attend with the purpose of experiencing the golf course and cheering on the players.

However, no market demand studies have been conducted in the context of professional golf. Although studies have provided insight into the variables affecting attendance at professional golf tournaments, golf itself has unique characteristics as a professional sport. The lack of consideration of characteristics more specific to golf, such as the nature of the game (e.g., proximity to the players, scenery, walking the course) and event service (e.g., food, charity), may limit the usefulness of previous studies. The extent to which the findings of previous studies are applicable to the setting of specific sports events is also unclear (Zhang et al., 2005). The weaknesses of previous studies may in part arise from the lack of a valid assessment tool to measure spectator satisfaction with the market demands of specific sports events (Zhang et al., 2005). In addition, sport spectators may expect more than the core product when they attend a sports event. 


\section{Peripheral Services at Sports Events}

The quality of peripheral services that contribute to improving spectator satisfaction has received more attention (e.g., Wakefield \& Sloan, 1995; Murray \& Howat, 2002; Hill \& Green, 2000) than the spectators' psychological factors, which are difficult for marketers to control. In particular, hospitality, scoreboards, accessibility, and food service are essential factors. One of the pleasures of spectators is the hospitality offered, and event service at a sporting event involves pleasing a large number of people (Mullin, Hardy, \& Sutton, 2007). Wakefield and Sloan (1995), Wakefield et al. (1996), and Hill and Green (2000) all mentioned the importance of service quality at stadiums.

Wakefield and Sloan (1995) developed the "hypothesized sportscape model" based on service quality. This model includes stadium parking, stadium cleanliness, fan behavior control, food service, crowding, and the effect of these factors on spectators' desire to stay. Spectators themselves have reported that stadium service is important (Greenwell, Fink, \& Pastore, 2002; Murray \& Howat, 2002). Hill and Green (2000) cited the differences in service factors that influence re-patronage intentions according to the type of stadium and the spectators who go there. Moreover, Hill and Green (2000) found that the distance between the parking and the stadium affects attendance. Wakefield and Sloan (1995) and Wakefield et al. (1996) found that parking and stadium access increase the spectators' enjoyment of the stadium and their desire to stay. Wakefield and Sloan (1995) stated that providing spectators with a shuttle bus to the stadium relieves traffic congestion and is a factor in keeping spectators at the stadium until the end of the game.

Hansen and Gauthier (1989) found that game schedules, convenient parking and team records strongly affect spectators. The differences between indoor and outdoor sports are determined by economic factors. Melnick (1993) noted that physical factors such as the design of the stadium, the quality of food service and the interchange with the fans affect stadium experience, as reported by spectators. However, when considering sports events comprehensively, core products such as player appeal, game details, and competition characteristics are also important (Mullin et al., 2007).

Based on these findings, further research is needed to understand spectator satisfaction according to segmentation of core products and peripheral services.

\section{Research Questions}

Robinson, Trail, and Known (2004) indicated that attending a professional golf tournament is different from attending a baseball or football game, in that the 
spectator is watching specific athletes rather than teams. In addition, Barkow (1989) stated that, regardless of the viewing perspective taken, the spectator will miss the majority of the action. At other sports competitions, the spectators sit in an arena or stadium. Whereas research on conventional spectator behavior, service quality and spectator satisfaction has examined the behavior of spectators attending team sports competitions, this study conducts spectator research relative to an individual sport. Moreover, there is no established body of literature on this topic.

From our review of previous studies, we suggest the following conceptual framework for a golf tour tournament (Figure 1).

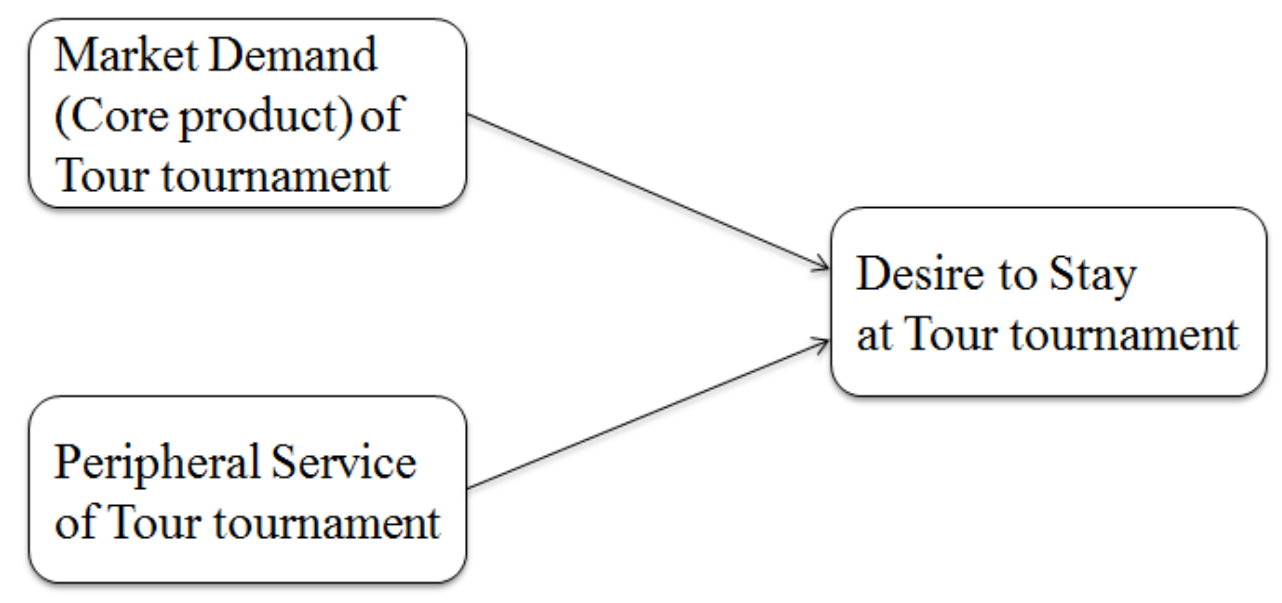

Figure 1. Conceptual Model of a Golf Spectator’s Desire to Stay

\section{METHOD}

\section{Demographics of Golf Spectators in 2003-2006}

According to the Golf Tournament Promotion Association of Japan (GTPA) (2003-2006), the gender ratio of spectators of the Japan Golf Tour Association (JGTA) is $68.7 \%$ male and $31.3 \%$ female. By age, approximately $90 \%$ are over 30 years old and approximately $50 \%$ are over 50 years old. In addition, approximately $85 \%$ are amateur golfers, and approximately $60 \%$ attend tournaments using complimentary tickets. For the Ladies' Professional Golfers Association (LPGA) of Japan, $67.4 \%$ of the spectators are male and $32.6 \%$ are female. Approximately $40 \%$ of the people in these spectators are over 40 years old, approximately $82 \%$ are golf players, and approximately $50 \%$ attend by complimentary admission. 


\section{Instruments}

Several steps were taken to develop and validate this study for spectators at professional golf tournaments. The instruments were adapted and modified from previous golf-spectator research (Gauthier \& Hansen, 1993; Hansen \& Gauthier, 1993, 1994) and sports service-quality studies (Wakefield \& Sloan, 1995). The instruments were classified into the three dimensions of core product (affection for the players, fondness for the game of golf, course setting), peripheral service (hospitality and service management, accessibility), and desire to stay at the tour tournament. For the core product dimension, Hansen and Gauthier's original golf spectator scale was used, although some of the instruments were modified. For the peripheral service dimension, based on Wakefield and Sloan (1995), the physical-environment instruments were adapted and modified. In addition, the subscale of 'desire to stay' consisted of a combination of the items of Wakefield and Baker (1998).

The content validity of the initial survey was assessed prior to the study by a panel of sports management experts consisting of two tournament producers, sponsor personnel, and association officers, who were asked to examine the relevance of the content and the representativeness and clarity of the items on the questionnaire. The experts were invited to provide suggestions for revising the questionnaire. The wording of the questionnaire was verified by experienced golf gallery members $(n=$ 10). In the end, 23 items were used to predict spectators' staying behavior. These items were related to affection to the player (two items), preference for the game of golf (five items), the course setting (four items), hospitality and service management (eight items), accessibility (two items) and spectators' desire to stay (two items). The dimensions of the core product and the spectators' desire to stay were measured on a 6-point Likert-type scale ranging from "strongly disagree” (1) to "strongly agree” (6), whereas the event operation dimensions were measured on a 6-point Likert-type scale ranging from "very dissatisfied" (1) to "very satisfied" (6).

\section{Pilot Test}

A pilot survey was conducted using a stratified sampling of spectators at a Japanese professional golf tournament during the 2006 season. Of the 256 surveys collected, 228 usable surveys were returned, resulting in a response rate of $89.0 \%$.

After pilot data collection, exploratory factor analysis was conducted to identify the dimensionality of the research scale over the 23 items. This analysis resulted in the items being loaded onto five factors, which explained $63.5 \%$ of the total variance in the factor model. However, six items were eliminated due to factor loadings below .50 
(Hair, Anderson, Tatham, \& Black, 1998). The results of this procedure yielded a 5 -factor model with 17 items that were deemed appropriate for further analysis.

The data from the pilot tests were examined to assess the reliability of the survey items and to investigate how well each question represented a specific antecedent factor. Item-total analysis revealed a stable sub-scale structure for each dimension with internal consistency measures ranging from .70 to .87 (Nunnally \& Bernstein, 1994). Following these procedures, five factors were composed for affection to the player (two items), preference for the game of golf (four items), course setting (two items), hospitality and service management (five items), accessibility (two items), and desire to stay (two items).

\section{Main Study (Participants and Data Collection)}

The research participants in this study were selected from spectators at two professional golf tour tournaments in Japan using a quota sampling method. Using a stratified sampling method, the gender composition of the sample subjects had a ratio of 7 men to 3 women. The sample subjects of the study were designated to be at least 30 years of age (The Golf Tournament Promotion Association of Japan Inc., 2003-2006). A written questionnaire was distributed to golf spectators at the food court and entrance hall. At that time, students majoring in sports management who had been trained for the survey distributed and collected questionnaire surveys from spectators who grasped the course by monitoring tournament progress and walking the entire course and spectators on their return.

Of the 991 questionnaires distributed, 943 usable questionnaires were collected, resulting in a return rate of $95.1 \%$. The data collected from the questionnaires showed that $65.0 \%$ of the respondents were male and $35.0 \%$ were female. Approximately $31.9 \%$ of the respondents were 60 years of age or older, $29.5 \%$ were $50-59$ years old, $20.7 \%$ were $40-49$ years old, and $17.9 \%$ were $30-39$ years old. The vast majority of spectators were golf players: $28.8 \%$ played $1-10$ rounds per year, $28.0 \%$ played $11-25$ rounds per year, and $27.8 \%$ played 26 rounds or more. With regard to the ticket type of the respondents, $60.4 \%$ obtained complimentary tickets and $17.3 \%$ had advance tickets, and $21.3 \%$ had daily tickets. Most of the participants attended the event with family or friends, with only $16.9 \%$ of the participants reporting that they attended the event alone.

Data analysis was performed using Amos 16.0 and SPSS 16.0. Confirmatory factor analysis (CFA) was used to identify the construct validity for all latent dimensions. Additionally, structural equation modeling (SEM), which examines the 
direct and indirect relationships among the dimensions of the hypothetical model, was conducted using Amos 16.0.

\section{RESULTS}

Confirmatory factor analysis results revealed that the key factors for construct validity were obtained using various model fit indices. The comparative fit index (CFI $=.926)$, goodness of fit index (GFI $=$. 923), normed fit index (NFI = .910), Tucker-Lewis index (TLI $=.900)$ and root mean square error of approximation $($ RMSEA $=.075)$ were all at acceptable levels (CFI, GFI, NFI, TLI > .90, RMSEA $<.08$; Kline, 2005; Hair et al., 1998).

According to the results of the CFA, the latent constructs examined in this study were satisfactory in terms of construct validity. Furthermore, the factor loadings ranged from .65 to .88, and the individual subscale reliabilities ranged from .68 to .89, indicating adequate internal consistency, with the exception of accessibility, which was benchmarked according to the value of .70 (Nunnally \& Bernstein, 1994). In addition, the average variance extracted (AVE) ranged from .51 to .63; for six factors, the values exceeded the recommended .50 cutoff (Fornell \& Larcker, 1981). The data analysis suggested that the overall reliability of the factors was acceptable (Table 1). For correlations among the constructs, Kline (2005) defined a correlation below .85 as within the validity range. The intercorrelation values ranged from .25 to .68.

Conceptual models were constructed to examine the relationship among the dimensions of the "market demand factor" (affection to the players, preference for the game of golf, course setting), "peripheral service factor" (hospitality and service management, accessibility), and "spectators' desire to stay". The results of SEM for the conceptual model indicated an acceptable fit to the data (CFI $=.917$, GFI $=.911$, NFI $=.901$, TLI $=.900$, RMSEA $=.079)$. Affection for the player, fondness for the game of golf and course setting, which represented the core products, significantly influenced the spectators' desire to stay (affection to the player: $r=.18, p<.05$; preference for the game of golf: $r=.16, p<.05$; course setting: $r=.22, p<.001$ ). In addition, among hospitality and service management and accessibility, which represented peripheral service, only the dimension of hospitality and service management significantly influenced the spectators' desire to stay (hospitality and service management: $r=.34, p<.001$; accessibility: $r=-.06$, n.s.). Based on these results, the hospitality and service management factor had the strongest influence on the spectators' desire to stay, which indicates that the core product was an important factor in spectators' desire to stay. The conceptual model explained approximately 
$45 \%$ of the variance in the spectators' desire to stay (Figure 2).

Table 1 Results of CFA for The Scale of Golf Spectator's Desire to Stay

\begin{tabular}{|c|c|c|c|c|c|}
\hline & Factors & Items & $\begin{array}{l}\text { Factor } \\
\text { Loding }\end{array}$ & Reliability & AVE \\
\hline \multirow{8}{*}{$\begin{array}{l}\text { Core } \\
\text { Product }\end{array}$} & \multirow{2}{*}{$\begin{array}{l}\text { Affection to } \\
\text { Player }\end{array}$} & To cheer for famous (big names) players & .79 & \multirow{2}{*}{.72} & \multirow{2}{*}{.57} \\
\hline & & To cheer for specific players & .65 & & \\
\hline & \multirow{4}{*}{ Game of Golf } & Golf is my favorite sports & .70 & \multirow{4}{*}{.82} & \multirow{4}{*}{.53} \\
\hline & & $\begin{array}{l}\text { To see live action - to be close to golfers, } \\
\text { feel presence }\end{array}$ & .85 & & \\
\hline & & $\begin{array}{l}\text { To see live action - players' practice close } \\
\text { to golfers }\end{array}$ & .74 & & \\
\hline & & $\begin{array}{l}\text { Pick up tips on shot making or others - to } \\
\text { learn players' skills }\end{array}$ & .72 & & \\
\hline & \multirow[t]{2}{*}{ Course Setting } & $\begin{array}{l}\text { To enjoy fitness benefits of walking golf } \\
\text { course }\end{array}$ & .77 & \multirow[t]{2}{*}{.79} & \multirow[t]{2}{*}{.61} \\
\hline & & To enjoy the scenery of golf course & .88 & & \\
\hline \multirow{7}{*}{$\begin{array}{l}\text { Peripheral } \\
\text { Service }\end{array}$} & \multirow{5}{*}{$\begin{array}{c}\text { Hospitality } \\
\text { and } \\
\text { Service } \\
\text { Management }\end{array}$} & The food service, the shop and so on & .70 & \multirow{5}{*}{.89} & \multirow{5}{*}{.63} \\
\hline & & $\begin{array}{l}\text { The charity event (e.g. talking show, } \\
\text { autograph session and so on) }\end{array}$ & .67 & & \\
\hline & & $\begin{array}{l}\text { Event guidance (setting place of } \\
\text { signboard, high quality scoreboard, fan } \\
\text { control) is appropriate }\end{array}$ & .88 & & \\
\hline & & $\begin{array}{l}\text { Event staff and volunteer staff treat us } \\
\text { hospitably }\end{array}$ & .87 & & \\
\hline & & $\begin{array}{l}\text { The number of restrooms and cleanliness } \\
\text { are maintained }\end{array}$ & .77 & & \\
\hline & \multirow[b]{2}{*}{ Accessibility } & Easy access to golf course (parking area) & .65 & \multirow[b]{2}{*}{.68} & \multirow[b]{2}{*}{.51} \\
\hline & & $\begin{array}{l}\text { A lot of pick-up shuttle buses to golf } \\
\text { course }\end{array}$ & .78 & & \\
\hline \multirow{2}{*}{\multicolumn{2}{|c|}{ Desire to stay }} & $\begin{array}{l}\text { I enjoy spending time at the tour } \\
\text { tournament }\end{array}$ & .82 & \multirow{2}{*}{.77} & \multirow{2}{*}{.56} \\
\hline & & $\begin{array}{l}\text { I like to stay at the tour tournament as } \\
\text { long as possible }\end{array}$ & .72 & & \\
\hline
\end{tabular}




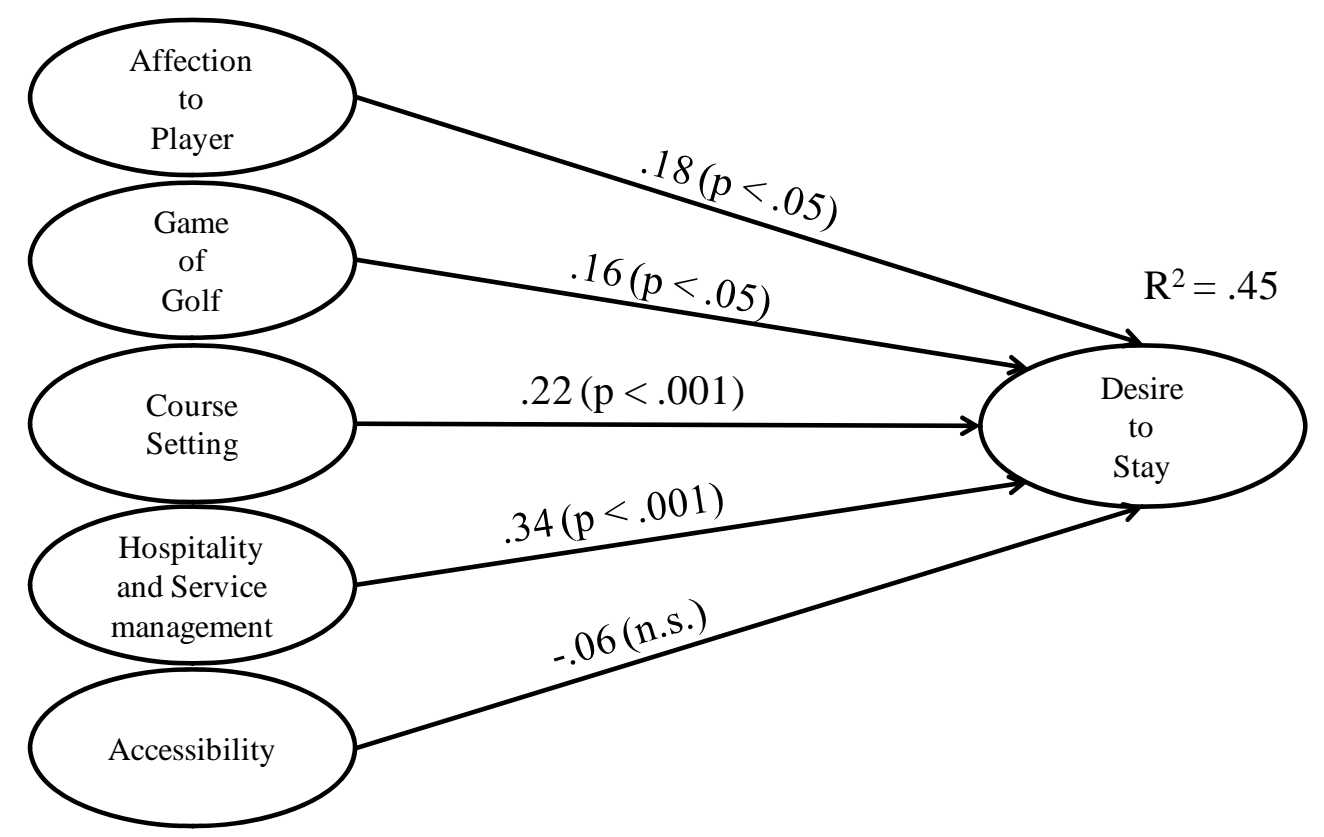

Figure 2 Analysis Results of Spectators’ Desire to Stay at a Tour Tournament

\section{DISCUSSION}

The purpose of this study was to examine which variables most influence golf spectators' desire to stay at professional golf tournaments in Japan. The results indicated that affection for the players, fondness for the game of golf, the course setting and hospitality and service management were significantly related to the spectators' desire to stay. The hospitality and service management factor had the strongest effect on the spectators' desire to stay, while the other attendance factors (affection for the players, fondness for the game of golf, the course setting) also affected the spectators' desire to stay. However, accessibility was not significantly related to the spectators' desire to stay.

Concerning the factor of affection for the players, similar findings were obtained by Zhang et al. (1995, 1997, 2003, 2005), which found the player factor to be the most influential in determining whether a spectator would watch a game. Moreover, Robinson et al. (2004) found a relationship between vicarious achievement and attachment to players in a tournament; because golf has no teams, golf fans often live vicariously through the success of their favorite golfer. This result is a unique characteristic of professional golf. Because the player factor has an influence on the spectators' desire to stay, it may also influence the interest of the spectator and/or spectator behavior at the event. However, in this study, loyalty to and support of 
players were not examined in depth. In addition, Yoshida and James (2010) suggested that player performance may not influence event satisfaction. Based on these contradictory results, further investigations of the influence of affection to and support of players on the spectators' desire to stay are needed.

With regard to the factor of fondness for the game of golf, for example, it has been speculated that "golf is love" or "to see the play or practice close to the players" are characteristic reasons for spectators to attend golf tournaments. A spectator watching a baseball or soccer game in a stadium has a designated seat and area. However, at tour tournaments, spectators are much closer to the players. Hansen and Gauthier (1994) explained that “Unique spectator reasons, such as making one’s own decision as to who and where to watch, being close to golfers, and enjoying the fitness benefits of walking a few hundred acres of attractive landscape in the fresh air, can differentiate golf events from virtually all other spectator sport events." These conditions affect spectator motives and are likely to have an influence on the spectators' desire to stay (Hansen \& Gauthier, 1993, 1994; Robinson \& Carpenter, 2002).

Course setting was also significantly related to the spectators' desire to stay. Gauthier and Hansen (1993) suggested that golf should offer spectators the uniqueness of local scenery, wellness accept of environment, and the features of the course, in addition to the game itself. For people who are watching professional golf, player appeal, the improvement of their own golf skills, course scenery, and other features become the core products (Hansen \& Gauthier, 1993). This study also found that these factors are core products for spectators of professional golf, thus supporting the results of previous studies (e.g., Greenwell et al., 2002, Tsuji et al., 2007).

Hospitality and service management had the strongest effect on the spectators' desire to stay. For example, most spectators attended a tour tournament to watch the best players. When a spectator arrives at the event, he or she wishes to know which player was at which hole, and how the players are ranked. Spectators expect immediate answers to these questions from the marketer or event organizer, and may influence their desire to stay. In addition, most spectators also expect food service or variety shops.

A tour tournament is a daylong event. How does the marketer or organizer satisfy spectators and keep them comfortable? Prior studies (e.g., Greenwell et al., 2002; Hill \& Green, 2000; Wakefield et al., 1994, 1995, 1996) have found that high-quality food service, directions and staff satisfy customers, and this study supports these findings. Therefore, at tour tournaments, event service is indispensable for an enjoyable 
daylong spectator experience.

However, Greenwell et al. (2002) reported that by classifying customer satisfaction hierarchically, customer satisfaction was found to differ with regard to staff service, while other physical factors did not have an influence on satisfaction. Hill and Green (2000) reported that factors such as stadium service, loyalty and involvement responsible for influencing future attendance vary by the type of stadium and spectator. Further studies are thus needed to investigate in greater detail this relationship between spectator and service.

\section{CONCLUSIONS}

The purpose of this study was to clarify how core products and service evaluations influence a golf spectator's desire to stay at a tour tournament and to understand more about the behavior of spectators at professional golf tournaments. The physical environment has been found to influence the spectators' desire to stay (Wakefield \& Sloan, 1995; Wakefield \& Baker, 1998). However, the results of this study showed that both the physical environment and the core products influence the spectators' desire to stay. In other words, factors that influence the spectators' desire to stay will also affect their satisfaction.

In addition, event service had a strong effect on the desire to stay. As mentioned earlier, tour tournaments are daylong events. Therefore, careful management is required to keep the spectators from becoming bored and leaving early. For example, a spectator may wish to watch a favorite player who plays from tee-off to hole-out for four hours. Then, the spectator may be hungry while watching the tournament or may be interested in the club setting or in the color that the golfer wears or the brand that he or she endorses. Therefore, putting a great effort into food, charity events, and staff service will satisfy the spectator and will make the main purpose of attending -watching the game - even more enjoyable. Furthermore, tournament management should offer "spectator service that becomes a benefit to the spectator's golf, such as introduction of the player's club setting and golf wear of the player," "quality control of the course and the grass for easy walking by spectators" and "privileges (e.g., a discount for food or goods) for women spectators”. Furthermore, event organizers may provide finger foods so spectators can eat while watching the tourney, and it may be beneficial to give privileges according to the steps taken while walking.

The present study has some limitations. The sample used in this study represented only two tournaments near Tokyo, Japan. As Robinson et al. (2004) pointed out, differences in the site of the tournament may be associated with 
differences in spectator motives and attachment. Therefore, in future studies, it will be necessary to determine spectator behavior with a more detailed segmentation (taking into consideration differences in gender, age, day, ticket type, tournament sponsor, tour, and site). Furthermore, in developing spectator studies of further tour tournaments, it is important to include focus group interviews with spectators and to use both quantitative and qualitative data. We would like to propose these steps as directions for future research.

\section{REFERENCES}

Barkow, A. (1989). The history of the PGA tour. New York: Doubleday.

Bitner, M. J. (1992). Servicescapes: The impact of physical surroundings customers and employees. Journal of Marketing, 56, 57-71. http://dx.doi.org/10.2307\%2F1252042

Braunstein, J. R., Zhang, J. J., Trail, G. T., Gibson, H. J. (2005). Dimensions of market demand associated with Major League Baseball Spring Training: Development of a scale. Sport Management Review, 8(3), 271-296. http://dx.doi.org/10.1016\%2FS1441-3523\%2805\%2970042-5

Fornell, C., \& Larcker, D. F. (1981). Evaluating structural equation models with unobservable variables and measurement error. Journal of Marketing Research, 18, 39-50. http://dx.doi.org/10.2307\%2F3151312

Funk, D. C., Mahony, D. L., Nakazawa, M., \& Hirakawa, S. (2001). Development of the Sport Interest Inventory (SII): Implications for Measuring Unique Consumer Motives at Team Sporting Events. International Journal of Sport Marketing \& Sponsorship, September/October, 291-316.

Gauthier, R., \& Hansen, H. (1993). Female spectators: Marketing implications for professional golf events. Sport Marketing Quarterly, 2(4), 21-28.

Greenwell, T. C., Fink, J. S., \& Pastore, D. L. (2002). Assessing the influence of the physical sports facility on customer satisfaction within the context of the service $\begin{array}{llll}\text { experience. Sport Management Review, 5, 129-148. } & \text {. }\end{array}$ http://dx.doi.org/10.1016\%2FS1441-3523\%2802\%2970064-8

Hair, J.F., Anderson, R.E., Tatham, R.L., \& Black, W.C. (1998). Multivariate data analysis. Upper Saddle River, NJ: Prentice-Hall.

Hansen, H., \& Gauthier, R. (1989). Factor affecting attendance at professional sport event. Journal of Sport Management, 3, 15-32.

Hansen, H., \& Gauthier, R. (1993). Spectators' views of LPGA golf events. Sport Marketing Quarterly, 2(1), 17-25. 
Hansen, H., \& Gauthier, R. (1994). The professional golf product: Spectators’ views. Sport Marketing Quarterly, 3(4), 9-16.

Hill, B., \& Green, B. C. (2000). Repeat attendance as a function of involvement, loyalty, and the sportscape across three football contexts. Sport Management Review, 3, 145-162. http://dx.doi.org/10.1016\%2FS1441-3523\%2800\%2970083-0

Kline, R. B. (2005). Principles and practice of structural equation modeling ( ${ }^{\text {nd }}$ ed.). New York: Guilford Press.

Mahony, D. F., \& Moorman, A. M. (2000). The impact of attitudes toward athletes on the behavioral intentions of professional football and professional basketball fans. Sport Marketing Quarterly, 9, 31-139.

Melnick, M. J. (1993). Searching for sociability in the stands: A theory of sports spectating. Journal of Sport Management, 7, 44-60.

Milne, G. R., \& McDonald, M. A. (1999). Sport marketing: Managing the exchange process. Sudbury, MA: Jones \& Bartlett.

Mullin, B.J., Hardy, S., \& Sutton, W.A. (2007). Sport marketing ( ${ }^{\text {rd }}$ ed.). Champaign, IL:Human Kinetics.

Murray, D., \& Howat, G., (2002). The relationships among service quality, value, satisfaction, and future intentions of customers at an Australian sports and leisure $\begin{array}{llll}\text { centre. } & \text { Sport } & \text { 25-43. }\end{array}$ http://dx.doi.org/10.1016\%2FS1441-3523\%2802\%2970060-0

Nunnally, J. C., \& Bernstein, I. H. (1994). Psychometric theory ( $3^{\text {rd }}$ ed.). New York, NY: McGraw-Hill.

Robinson, M. J., \& Carpenter, J. R. (2002). The day of the week’s impact on selected socio-demographic characteristics and consumption patterns of spectators at a LPGA event. Sport Marketing Quarterly, 11(4), 242-247.

Robinson, M. J., Trail, G. T., \& Kwon, H. (2004). Motives and points of attachment of professional golf spectators. Sport Management Review, 7, 167-192.

Trail, G. T., \& James, J. D. (2001). The motivation scale for sport consumption: Assessment of the scale's psychometric properties. Journal of Sport Behavior, 24(1), 108-127.

The Golf Tournament Promotion Association of Japan Inc. (2003-2006). Tour tournament research.

Tsuji, Y., Bennett, G., \& Zhang, J. (2007). Consumer satisfaction with an action sports event. Sport Marketing Quarterly, 16(4), 199-208.

Wakefield, K. L. \& Barker, J. (1998). Excitement at the mall: Determinants and effects on shopping response. Journal of Retailing, 74(4), 515-539. 
http://dx.doi.org/10.1016\%2FS0022-4359\%2899\%2980106-7

Wakefield, K.L. \& Blodgett, J.G. (1994). The importance of servicescapes in leisure service settings. Journal of Services Marketing, 8, 66-76. http://dx.doi.org/10.1108\%2F08876049410065624

Wakefield, K.L., \& Blodgett, J.G. (1996). The effect of the servicescape on customers' behavioral intentions in leisure service settings. Journal of Services Marketing, 10(6), 45 - 61. http://dx.doi.org/10.1108\%2F08876049610148594

Wakefield, K. L., \& Sloan, H. (1995). The effects of team loyalty and selected stadium factors on spectator attendance. Journal of Sport Management, 9, 153-172.

Wakefield, K. L., Blodgett, J. G., \& Sloan, H. (1996). Measurement and management of the sportscape. Journal of Sport Management, 10, 15-31.

Yoshida, M. \& James, J. D. (2010). Customer Satisfaction With Game and Service Experiences: Antecedents and Consequences. Journal of Sport Management, 24, 338-361.

Zhang, J. J., Lam, E. T. C., \& Connaughton, D. P. (2003). General market demand variables associated with professional sport consumption. International Journal of Sports Marketing and Sponsorship, 5(1), 33-55.

Zhang, J. J., Lam, E. T. C., Connaughton, D. P., Bennett, G., \& Smith, D. W. (2005). Development of a scale to measure spectator satisfaction toward support programs of minor league hockey games. International Journal of Sport Management, 6(1), 47-70.

Zhang, J. J., Pease, D. G., Hui, S. C. \& Michaud, T. J. (1995). Variables affecting the spectator decision to attend NBA games. Sport Marketing Quarterly, 4(4), 29-39.

Zhang, J.J., Pease, D.G., Smith, D.W., Lee, J.T., Lam, E.T.C., \& Jambor, E.A.(1997). Factors affecting the decision making of spectators to attend minor league hockey games. International Sports Journal, 1(1), 39-54. 